\title{
A CONSTITUIÇÃO DE REPRESENTAÇÕES DAS HISTÓRIAS DAS MULHERES NA MUSEALIZAÇÃO DO MUSEU JULIO DE CASTILHOS (1995-1998): a agência das intelectuais mediadoras
}

Andréa Reis da Silveira*

RESUMO: O artigo se propõe a apresentar alguns resultados da investigação da tese de doutorado em História, na qual trato da constituição das histórias das mulheres no acervo do Museu Julio de Castilhos, entre os anos de 1995 e 2010. Especificamente, o presente texto analisa a incorporação de 143 objetos doados por mulheres entre 1995 e 1998, verificando a documentação museológica desses artefatos e o modo como foi constituída a sua transformação funcional (do real ao simbólico) pelas doadoras e funcionárias do museu, as primeiras intelectuais mediadoras. Foi possível perceber que as práticas e as representações das histórias das mulheres no Museu estiveram relacionadas com a conciliação das relações de poder, sobretudo na musealização, ainda que o objetivo se dispusesse à formação histórica dos escolares.

PALAVRAS-CHAVE: Museu Julio de Castilhos; História das mulheres; Representações; Musealização.

\section{La constitución de representaciones de las historias de las mujeres en la musealización del Museo Julio de Castilhos (1995-1998): la agencia de las intelectuales mediadoras}

RESÚMEN: El artículo se propone a presentar algunos resultados de la investigación de mi tesis doctoral en que analizo la constitución de historias de mujeres en el acervo del Museo Julio de Castilhos entre los años 1995 y 2010. Específicamente, el presente texto analiza la incorporación de 143 objetos donados por mujeres entre 1995 y 1998 verificando su documentación museológica y la manera como fueron constituidas sus transformaciones funcionales (del real al simbólico) por las donantes y encargadas del museo, las primeras intelectuales mediadoras. De hecho se percibió que las prácticas y las representaciones de las historias de las mujeres en el Museo estaban relacionadas con la conciliación de las relaciones de poder, especialmente en la musealización aunque el objetivo estaba destinado a la formación histórica de escolares.

PALABRAS CLAVES: Museo Julio de Castilhos; Historia de mujeres; Representaciones; Musealización.

\section{The constitution of representations of the stories of women in the musealization of the Julio de Castilhos Museum (1995-1998): the agency of mediating intellectuals}

ABSTRACT: The article proposes to present some results of the research of my doctoral thesis in which I analyze the constitution of stories of women in the collection of the Julio de Castilhos Museum between 1995 and 2010. Specifically, the present text analyzes the incorporation of 143 objects donated by women between 1995 and 1998, verifying their museological documentation and the way their functional transformations (real to symbolic) were constituted by the donors and museum staff members, the first mediating intellectuals. In fact it was perceived that the practices and representations of the stories of women in the Museum were related to the reconciliation of power relations, especially in musealization although the objective was aimed at the historical formation of school children.

KEYWORDS: Julio de Castilhos Museum; Stories of women; Representations; Musealization.

\footnotetext{
*Mestra em Patrimônio Cultural pela Universidade Federal de Santa Maria/UFSM. Atualmente é doutoranda em História pelo Programa de Pós-Graduação em História (PPGH) da Universidade do Estado de Santa Catarina (UDESC). Contato: Av. Me. Benvenuta, 2007, Itacorubi, CEP: 88035-901, Florianópolis, SC, Brasil. E-mail: andrears1965@gmail.com, ORCID: http://orcid.org./0000-0010-5998-0865.
} 
Neste artigo, demonstro breves desfechos das análises sobre as incorporações realizadas no Museu Julio de Castilhos, no recorte do período entre 1995 e 1998. Investigo a extremidade da construção do processo museológico de narrativas sobre mulheres a partir da consulta exclusiva das ações de doação de acervos, da documentação museológica, do fichário catalográfico das informações e, principalmente, dos arquivos de registro com dados sobre os(as) doadores(as) que incidiram sobre as coleções.

A documentação museológica como processo que musealiza objetos é a fonte a ser explorada para a compreensão do modo como o Museu deu vida aos objetos após a sua mudança de estado, de funcional a simbólico. Portanto, é por meio dela que se pode perceber o que, como e porque o Museu coletou, pesquisou, conservou e expôs determinadas peças em detrimento de outras.

Constatei que a maior parte das ofertas de peças foi realizada por doações de mulheres, o que garante uma cumplicidade entre o corpo funcional do museu e as doadoras na construção de uma narrativa mediada de conflitos, ou o que Paul Ricouer (2001) configurou como "concordância dos discordantes".

A questão que se segue é como foram acionadas pelos intelectuais mediadores as histórias das mulheres? Como as peças doadas foram empregadas na interação de narrativas propostas pelo museu? Em que lugar se encontram as mulheres nessas narrativas fabricadas na musealização dos intelectuais mediadores?

Verifiquei que os sentidos atribuídos pendem para o posicionamento centrífugo (CARVALHO, 2008) das histórias das mulheres, nas coleções e narrativas desenvolvidas, com intercalação da ausência e da presença delas nas materialidades examinadas. A memória e a história das mulheres se fazem alicerçadas em relações de poder e violências simbólicas, cujo desafio historiográfico é superar esses confrontos pelo estudo das posições e das relações (CHARTIER, 2002). No caso de presenças, essas se registram conforme conveniência de reforço de identidades nas memórias e histórias, ou pelas subjetividades do grupo de agentes que atuam na instituição.

Assim, o espaço museológico do MJC é convertido como propício para reflexão e análise das inclusões, dos obstáculos e dos desafios que se conferem aos estudos da cultura material. No viés das minorias historicamente obliteradas no cenário das discussões, como as mulheres foram e ainda o são, esse é um objeto inédito e relevante para as discussões da história do tempo presente, interessada na falência das narrativas únicas, totalizantes, no tempo móvel do presente e das subjetividades. 


\section{A construção de narrativas a partir da musealização de objetos e a ação dos intelectuais mediadores}

As experiências que o MJC se propõe a possibilitar despertam atenção pelos mecanismos e pelas ferramentas empregadas, que instituem permanências e mudanças nas sociedades desse tempo presente. Os documentos materiais produzidos como narrativas históricas pelo Museu não são mera transmissão, mas despertam sentidos sobre processos históricos, memórias e histórias que podem conduzir a diferentes possibilidades de expectativas em horizontes diversos de pretérito. O Museu, espaço de cultura e formação, pode contribuir como lugar de aceitação, na reflexão pela discussão, a respeito das atribuições de gênero e representação das mulheres na história do Rio Grande do Sul.

Desde sua criação em 1903, o MJC é vinculado ao Governo do Estado do Rio Grande do Sul, tendo seus recursos financeiros, materiais, humanos e outros ligados aos repasses disponíveis no orçamento que lhe diz respeito. A aquisição no MJC está pautada, essencialmente, nas contribuições da sociedade para o engrandecimento do museu, atualmente composto por mais de 11 mil peças distribuídas na catalogação de 29 coleções.

Há várias possibilidades de um museu ampliar seu acervo, reforçando suas reservas técnicas e investindo em pesquisas para oportunizar novas perspectivas de produção de conhecimento. O campo museal (POSSAMAI, 2010) denomina a prática de transformar peças do uso comum em signos e símbolos de representação material como musealização (STRÁNSKY, 1995), que pode ser compreendida como um processo permanente de rearticulação, na atribuição de valores e significados além da função de uso e consumo para o qual a peça foi produzida.

A musealização se dá na cadeia operatória das atividades dos museus e, por si só, já é um procedimento que define substituição de uma realidade da função original da peça para o contexto testemunhal. No MJC, o caráter da musealização pode ser visto como de monumentalidade. Pretende, assim, celebrizar, eternizar alguém ou algum acontecimento do passado, mas não significa dizer que musealizar seja sacralizar uma peça, embora isso possa ocorrer.

Do mesmo modo, não se atribui ao museu a condição de colecionador, mesmo que em outras épocas essa visão já tenha prevalecido. Tais perspectivas posicionam os museus como ambientes fúnebres, o que de fato já se sucedeu no pretérito. A musealização gera museália, objeto/peça que recebeu status de peça museológica, constituinte de experiências repletas de testemunhalidade passada, no tempo e espaço de acontecimentos, pessoas, atos, situações das 
vivências humanas. A museália, peça, ou coleção, evoca memórias que oportunizam revisitar experiências comuns e dissonantes da experimentação histórica (RÜSEN, 2007). Desde a década de 1970, a conotação de sentido para essa experimentação vem sendo problematizada, e os museus procuram alterar, com avanços e recuos, as suas posturas em relação ao atendimento a transformação social como demanda de cooperação em suas missões institucionais.

Das seleções realizadas e das produções narrativas resultantes do processo museológico a partir desses objetos, definem-se os rastros (RICOUER, 2007) que serão protagonizados. Arrisco traçar um comparativo do universo dos museus com o dos historiadores, haja vista que ambos usufruem da dialética do tempo entre passado e presente para lidar com a sociedade e refletir sobre ela, mas também atuam como organizadores de narrativas que podem ser movimentadas e reconfiguradas.

O museu, portanto, é fruto do seu tempo, com operações didáticas de responsabilidade na formação histórica, entendida na acepção de Jörn Rüsen (2007) como um modo próprio de experimentação da aprendizagem que acarreta efeito na vida prática dos sujeitos envolvidos, proporcionando-lhes competência para interpretar a si e o próprio mundo.

A musealização do MJC é de caráter regional. É satisfatório apontar três momentos distintos de critérios e práticas de coleta, demonstrando que a instituição não é um templo de peças sacralizadas, mas um espaço cujas representações são resultado de práticas que podem ressignificar figuras forjadas de um passado, ganhando forte repercussão de sentidos no presente. Para melhor compreensão, segue uma breve recapitulação desse tripé aquisitivo de objetos para o acervo, e neles se pode perceber regimes de historicidade (HARTOG, 2015) de um passado de glórias, um presente que se quer modificado, para um futuro em perspectiva.

Aos moldes de seus pares elaborados no contexto do século XIX e início do XX, nos seus primeiros anos o MJC teve suas coleções moderadas no entendimento do enciclopedismo, no evolucionismo, na crença da ciência como possibilidade de explicação do mundo e, sobretudo, na ideia de engrandecimento do estado. Os primeiros objetos foram representantes do ecletismo que caracterizava as coleções, compostas por animais taxidermizados, minerais, plantas, produção regional de produtos, além da produção artística e de alguns documentos históricos.

Essa configuração se sustentou até a década de 1950. Em 1958, um decreto estadual determinou que se desmembrasse o acervo conforme suas tipologias, acarretando a distribuição das coleções para instituições museológicas em decurso de criação no âmbito do 
Rio Grande do Sul. No entanto, para Ana Celina Silva (2018), já nos anos 1920, já se revelava uma assimilação de um perfil de museu histórico por parte do MCJ. Nessa perspectiva, o Museu formou suas coleções no juízo de um passado material e visual de história riograndense, cuja perspectiva era celebrativa e consagradora de feitos, fatos e personagens de destaque na historiografia oficial do estado.

Ainda me referindo ao segundo ciclo de composição de acervo, já com caráter de história regional, Silveira (2011) identifica que nos anos 1960-1970 a atribuição do MJC se manteve na disposição de fortalecer o vínculo imaginário e representativo dos objetos, numa história de bravura e heroísmo das façanhas militares na função da manutenção das fronteiras e da nacionalidade brasileiras, expressas na história do estado. Essa história é, sobretudo, referente aos homens que se salientaram no evento-chave da história rio-grandense, a Revolução Farroupilha (1835-1845), formador das identidades e representações do estado.

Não à toa, a maior parte das aquisições no período foram dentro das coleções de iconografia e indumentária militar, como realçou o texto de Silveira (2011) ao identificar que, entre os anos 1967-1971, o recolhimento foi de um volume intenso de peças de cunho bélico e militar, como uniformes, armamentos, condecorações e imagens de combatentes. Nessa temporada, a instituição esteve sob administração de um general, o que solidifica a questão da construção de história e memória conforme a interpretação, a ressignificação e a ênfase a determinadas noções e certos valores, revigorando o campo museal e patrimonial como desprovido de neutralidade, disputado na hegemonia do conhecimento histórico.

A realização das novas aquisições do MJC, a contar da década de 1990, evidencia o paradoxo dos jogos do tempo em que se intercalam os regimes de historicidade. O marco temporal se deve a duas questões: a primeira referente a uma mudança no perfil de recolhimento dos objetos e a segunda pelo modo como essa mudança se concretizou: por meio de um plano operacional e teórico.

Nesse sentido, o plano se constitui como operacional porque se delineou em meio à criação da Secretaria de Estado da Cultura (SEDAC), com planejamento em parâmetros técnicos e teóricos dos campos de atuação e em programas de qualidade das instituições ligadas (MJC, 1998, p. 9-10). O caráter teórico foi acentuado com a lotação de novos agentes entre 1994-1995, quando foram efetivados por concurso público e contribuíram para redefinir o direcionamento histórico das narrativas do acervo do MJC. ${ }^{1}$

É importante destacar que “[...] por mais qualificados e responsáveis que fossem os técnicos concursados, faltava-lhes os conhecimentos fundamentais relativos aos 
procedimentos museológicos" (MJC, 1998, p. 8). O excerto sugere que as expectativas de profissionalização do museu e a definição de política de aquisição eram necessárias para conduzir o museu "ao terceiro milênio", isto é, trazer as práticas e representações de forma a ultrapassar desequilíbrios históricos.

As condições de não sistematização e desnormatização provocadas pelo desconhecimento de técnicas e métodos próprios da documentação museológica e da ausência de políticas de aquisição, que são especialidades da profissionalização de museólogo, acarretou problemas graves de dissociação de informações e, pior, relativizou recursos e possibilidades de aprendizagem, experimentação e imaginação histórica (RÜSEN, 2007) para os públicos escolares, que são centrais nas visitas agendadas ou espontâneas.

Além da administradora, como esteve composta a equipe de funcionários(as) do MJC, entre 1995 e 1998, considerados(as) no enquadramento da categoria de intelectuais mediadores (GOMES; HANSEN, 2016)? Essas profissionais, servidoras do estado, sinalizaram interesse frente à valorização da diversidade em todas as suas condições culturais? Estiveram favoráveis à diversidade no Museu, uma vez que foram a elas atribuídos a reconstrução da história e memória, metodologicamente e conceitualmente?

Não é sem razão que denomino a equipe de funcionários do MJC como agentes da musealização, como intelectuais mediadores (GOMES; HANSEN, 2016). Esses são, segundo Ângela de Castro Gomes e Patrícia Santos Hansen (2016), especificamente, os funcionários das instituições dedicados aos desafios da mediação cultural com uso político de uma linguagem dialógica para evidenciar posições e interesses. Foram esses agentes que, por meio da operação museológica, culminaram suas perspectivas históricas e ideológicas no MJC, em ações educativas e expositivas. As ações dos intelectuais mediadores no interior das instituições museológicas voltadas para o reconhecimento cultural dos públicos são mais do que contextualizadas no tempo em que vivem, elas são intervenções políticas, que fazem desses lugares museológicos alçadas políticas.

As narrativas exteriorizadas no Museu em representações de presenças e ausências de grupos, faixas etárias, etnias, identidades sexuais e demais categorias possíveis de análise, consequentemente, não têm neutralidade alguma. São fenômenos culturais contidos em espaços de tempos e lugares, assim como as concepções de história. Podem ser vistas como constitutivas de experiências das ações humanas, na imposição imediatista do presente que se estabelece como única alternativa. Crianças, jovens e até adultos, pelo Museu, podem ampliar suas expectativas para além dos acontecimentos desse tempo atual, compreendendo os 
entrelaçamentos, a partir das memórias que a musealidade compõe, advindos do passado e que têm ressonância nas relações do tempo presente.

De certa forma, as mediações dos agentes sobre os objetos se dão entre a permanência de tradições conhecidas e o diálogo com novas produções de interpretação, mas também na premeditação da celebração de si mesmos ou de seus entes queridos. A análise se torna mais específica com os dados das fontes, no tópico seguinte.

Identifico, inicialmente, os perfis dos intelectuais mediadores articulados ao MJC, nas suas autoridades de função. Um corpo funcional misto de homens e mulheres, na faixa de 3040 anos, com graduação em História e áreas afins. Foram concursados para atender a recente criação da Secretaria de Estado da Cultura do Rio Grande do Sul (SEDAC), nos cargos de técnicos em assuntos culturais. Suas responsabilidades no MJC se davam como pesquisadores, conservadores, restauradores, educadores, na gestão do acervo e em ações educativas, sob supervisão técnica e metodológica da diretora museóloga provisionada.

Alguns desses intelectuais mediadores tiveram vínculos associativos com o Instituto Histórico e Geográfico do Rio Grande do Sul (IHGRGS), outros com a participação sindical, ocasionando trocas simbólicas de interpretação e olhares históricos que favorecem e facilitam relacionamentos profissionais e estabilidade funcional para a instituição. A maioria desses agentes se manteve ativa e fixa na atividade do museu, garantindo coesão e regularidade de ação das práticas até 2006.

Outro dado relevante da análise é que houve aumento do número de mulheres nas funções do museu, e elas ascenderam suas participações ao cargo de direção da instituição, respectivamente, nos anos 1999-2002 e 2003-2006, períodos que fazem parte do contexto geral da investigação da tese. Essa presença majoritária das mulheres nas atribuições administrativas, técnicas e científicas da instituição MJC pode ser percebida numa perspectiva mais ampla de que suas carreiras foram reflexo da educação feminina, reverberada nas condições de trabalho. Entretanto, esse avanço no desenvolvimento social pela equidade na condição feminina não é aparente na constituição de história e memória apresentadas pelo Museu.

No período compreendido entre 1995 1998, ora examinado, o MJC esteve sob direção de uma museóloga provisionada, cujo conhecimento teórico e metodológico dos procedimentos corretos pressupus capaz de organizar as coleções e seu acesso, presumindo que, assim, facultaria conduzir as questões de gerenciamento do acervo e, quiçá, valorizar e flexibilizar a figuração das histórias das mulheres. Além disso, o assessoramento dos técnicos 
culturais - graduados em História e outras especialidades das áreas afins (restauradora, arquiteto, pedagogas, jornalista), recentemente chegados na instituição, compondo uma equipe interdisciplinar - resolveriam os entraves de requisitos e padrões de aquisição, uso e disponibilização das coleções.

Vale comentar brevemente que o aparecimento das histórias das mulheres não era novidade. Produzida pela historiografia desde os anos 1970, o tema estava nos paradigmas da História Cultural que o MJC abordou em reuniões, seminários e palestras ao longo da gestão 1995-1998. Ações culturais - como a exposição de fotografias da Federação das Mulheres Gaúchas; o painel Heroína de dois mundos, Anita Garibaldi; a exposição Retratos de casamento; e principalmente os cursos Jornada de História Cultural ${ }^{2}$ e A construção de mitos no mиseu - deveriam contribuir com a eclosão da relevância do Museu em aproximar-se das novas fontes, dos novos olhares, dos novos interesses em relação a documentos históricos e à interpretação da memória social em outros sujeitos e agentes. As tramas das histórias das mulheres, além de serem um componente histórico da identidade rio-grandense, operam com uma virada epistemológica da musealidade e da patrimonialização no MJC, o que não ocorreu.

Essas intelectuais mediadoras tiveram condições para articular amplamente as múltiplas situações do passado, ressonantes no presente, e ampliar as representações das mulheres para além da vida doméstica. No entanto, o foco se voltou para outro cenário mais em voga no campo dos museus da segunda metade do século $\mathrm{XX}$ : romper o isolamento e torná-los participativos da sociedade, acessíveis aos distintos segmentos, essencialmente em projetos de educação. Percebe-se, nas incorporações em geral da época, ênfase no propósito educativo das práticas museais e na utilização dos objetos para a didatização (RÜSEN, 2014). A didatização da história, definida em Jörn Rüsen (2014), é aplicada em vários lugares e de várias formas, com vistas a estabelecer consciência histórica, tendo relação direta com o presente. Esse movimento se deu de tal forma no MJC que culminou ao ponto de a instituição autodenominar-se "museu educador".

No MJC, alguns programas e projetos de "educação patrimonial" foram planejados e criados com dedicação a reflexão da história narrada, ampliando destaque sobre negros e índios, por exemplo. Mesmo assim, as leituras de mundo e a compreensão das diferenças prosseguiram cunhando o discurso da história ensinada pelas relações de dominação, como se pode perceber nas exposições de longa duração, ainda vigentes. 
As exposições de longa duração: - sala Indígena, sala Missões, Farroupilha e quarto de Julio de Castilhos - mantiveram o discurso linear colonial, imperial e republicano. O que de fato pode ser percebido é a adequação das necessidades escolares em seus conteúdos, as problematizações possíveis pelos objetos condensadas em narrativas metafóricas do passado regional.

As abordagens eram (e ainda são) superficiais, se não complementadas pelos esforços dos mediadores, estudantes de graduação na área das humanidades. Faltava refletir e propor circunstâncias que remodelassem a percepção dos visitantes sobre as desigualdades nas relações sociais, especialmente entre homens e mulheres no protagonismo da história.

Entre 1995 e 2010, foram adquiridos 1.324 objetos; porém, neste artigo ocupei-me em apresentar análise do quantitativo dos 257 objetos musealizados no contexto de 1995-1998. As aquisições do acervo do MJC eram desenvolvidas por intermédio da doação de pessoas da sociedade porto-alegrense e gaúcha. Os objetos chegavam na forma individual da peça, ou em seu conjunto, o que não era raro de acontecer. Para algumas pessoas, especialmente aquelas da rede de sociabilidades da direção, ao museu cabia a função de resguardar suas identidades e a condição de entes sociais, fazendo dele um verdadeiro depósito de suas próprias memórias. Incrivelmente se percebe que o MJC adotou para esses artefatos o que Walter Benjamim (1987) chamou de valor de culto, ou aura.

O ano de 1996 foi importante para as definições de acervo, em duas situações: foi criada uma comissão de acervo (MJC, 1998, p. 13) e foi feita a renovação das coleções. A comissão de acervo inaugurou um avanço para a definição de normas de aquisição e do uso desses recursos, coordenados para a finalidade a qual o Museu se propôs. A comissão era formada por dois funcionários, a direção e três membros externos ao MJC, com conhecimentos de história (mas não de museologia!).

As novas coleções, classificadas em cotidiano e sociedade, trabalho e história regional (regionalismo), foram produzidas a partir da realização de um seminário interno, dirigido aos funcionários da instituição, ministrado pelo então diretor do Museu Paulista da Universidade de São Paulo, o historiador Ulpiano Bezerra de Meneses. A proposta foi feita para reformular as exposições de longa duração do Museu, mas provocou a necessidade de atualização sobre as coleções e as definições classificatórias do acervo. Este passou a ser entendido, daí em diante, nas mesmas potencialidades daquele de referência, e, portanto, seria interessante segui-lo e adequá-lo. 
Uma vez que as doações foram realizadas por interesse de pessoas físicas e de instituições públicas e privadas, o caráter deliberativo da comissão de acervo do MJC foi de referendar o tombamento de peças. Seus integrantes recebiam definição do que seria aceito a partir de um conceito de história e de memória criado pelo Museu. No livro Diário de acervo, há registros de algumas das reuniões desse grupo, em que se explicita a importância de salientar o local, o regional, na cultura material salvaguardada com finalidade de escolarização conteudista, incremento das ações da cultura escolar.

O que se pode extrair dessa categorização em três tempos de aquisição de objetos do MJC, e suas práticas de gestão da cultura material, é que passa por diferentes regimes de historicidade (HARTOG, 2015). As práticas e representações que rondam as peças têm seus sentidos ressaltados conforme as definições socialmente construídas pelos seus agentes, em que se pode perceber: um passado do Museu de entendimento glorioso, que lança seus tentáculos no presente que se pretende reviver, porém combativo dessa permanência; e um futuro a ser construído na mobilização de diferentes protagonismos, inclusive o das mulheres.

\section{Doações e doadoras: analisando dados da musealização em favor da formação histórica da educação museal no MJC}

Indícios de representação de presenças e/ou ausências das mulheres nas coleções do MJC se tornam evidentes quando investigamos o processo museológico desenvolvido. A observação se pauta na categoria mobilizada por Vânia Carvalho (2008) como objetos de natureza "centrífuga", para designar as peças apontadas como da condição feminina, revertidas para uma posição de domesticidade e subalternidade. A autora itera que os objetos tridimensionais (e iconográficos) submetem-se às escolhas e aos valores de seus doadores.

Pela observação da documentação textual museal em fichas de inventário, classificação e catalogação, entendo que esta é uma opção dos funcionários que documentam a peça. Por meio dessas construções se perpetuam posicionamentos culturalmente tradicionais e antigos de referenciar a posição das mulheres, reforçada nas representações do acervo.

O museu é ambiente em que a materialidade da vida passada reverbera problematizações sobre relações sociais no tempo presente. Considerar suas práticas e representações é dar atenção, ainda pouco explorada pela historiografia, às condições de como a história e a memória foram produzidas no âmbito desses espaços. Utilizá-los como objetos de investigação, como fontes, permite recompor os passos das desigualdades de gênero que parecem se intensificar nas descrições definidas por essas ações. 
É a partir da musealização que é iniciado o processo de memória e história tornados narrativas museológicas. A continuidade técnica, discursiva e metodológica da musealização faz da peça documento e conhecimento, posteriormente difundidos em procedimentos de comunicação museal, como exposições e ações educativas. O processo de incorporar objetos não é simples como parece. Nele está inserido um conjunto de atributos operacionais, administrativos, jurídicos, técnicos e simbólicos, a priori pautados no planejamento institucional. Atualmente, a Lei $\mathrm{n}^{\circ} 11.904 / 2009$ define a obrigatoriedade desse planejamento.

No entanto, no MJC, o ciclo não foi realizado com eficiência. A operação incorporativa gerou documentos - como termos de doação, ficha de entrada, numeração de registro, catalogação e tombamento da peça - esvaziados de referenciais, principalmente nas relações de gênero, por estarem incompletos, equivocados ou inexistentes. Em 2004, com a implantação do banco de dados digital, o sistema Donato, a equipe do Museu optou por desconsiderar a trajetória de chegada da peça nesse regramento e suporte. As informações intrínsecas e extrínsecas, que deveriam estar nas fichas manuscritas e arquivadas, foram inseridas diretamente nas tabelas de identificação do sistema, sendo o único referencial de documentação do acervo.

A informatização das coleções é de fato um avanço, pela facilidade de recuperação e acesso das informações. No entanto, a alimentação e a atualização do sistema são trabalhos permanentes, de dedicação e conhecimento. Com o tempo, a obsolescência da ferramenta é problema que pode impedir e inviabilizar consultas, de modo que os registros documentais iniciais do processo de incorporação necessitam ter duplicidade documental, em formato de papel, a serem mantidos em arquivos permanentes e ativos. Além disso, deve-se atentar ao formato digital, com salvamento garantido.

Todavia, isso não aconteceu no MJC, problematizando a recuperação das informações. Caso a migração de dados tivesse sido feita dessa forma, a pesquisa do acervo e sobre ele seria facilmente recuperável. Do contrário, tal conhecimento estaria à mercê de ações políticas e sociais, e também do processo histórico encabeçado por agentes envolvidos em valores, estratégias, signos e intencionalidades, o que transparece um ideário subjacente sobre um passado de representação. Portanto, a entrada de um objeto na coleção do acervo do museu não é ato sem partido, mesmo que passe pelo crivo de uma comissão constituída por membros da sociedade. Sua dissolução e dissociação são também propositais para compreender os objetivos institucionais. 
É aceitável ter prudência, é recomendável ser cético com as afirmativas românticas, com as conclusões amenas ou com retóricas negacionistas. No uso e nas questões sobre acontecimentos das narrativas formuladas por esses agentes, fica o Museu e seus objetos propícios a essas imposturas. A fratura de discursos é um posicionamento que confunde o reconhecimento de referenciais do museu pelos públicos, é uma forma de intervenção de classes, etnias e grupos.

Não é minha proposta cometer anacronismos, de tal forma que, para substanciar a reflexão das ações de captação do acervo MJC em 1995-1998, examinei a documentação sobre o modo de adoção das equipes do quadro funcional para o conceito e o método na reunião dos objetos.

Os documentos técnicos (relatórios, livro Diário de acervo e banco de dados) mostraram a adoção de três linhas de coleção: cotidiano e sociedade, trabalho e história (como se as demais não transitassem na operação da dialética tempo e espaço). Em nenhuma circunstância se dirigem a questões de feminilidades ou masculinidades. No sistema Donato, as consultas cruzadas de dados mostram poucas inclusões de referenciais para objetos declarados como de história das mulheres. Aparecem termos como mulher, feminino, esposa, moça, menina e filha.

Dos objetos atinentes a tais teores, são materialmente apresentados como: colar, aquarela, certidão, fotos (a maior parte), livros, estojos, maquiagens, tecidos, guardanapos, roupas, crânio, múmia, calçados, chapéus, luvas, gargantilhas, perfumes, leques, relógios, panelas, fitas, xícara, camisola e espartilho, vestido, missal e colcha. Os papéis das mulheres na percepção do Museu são prioritariamente homogeneizados no julgamento da vida social, familiar, religiosa, doméstica.

Verifica-se a dimensão privada de suas representações, conservando o investimento na relação de subalternidade de poder, protagonismo social, histórico, econômico e cultural delas. A configuração do gênero é ideologizada na naturalização da experiência da elite da etnia branca submetida aos dogmas do matrimônio e da maternidade. Para Vania Carvalho (2008), o repertório dos objetos museais coloca e caracteriza a figura central do homem, sendo voltado para a individualização das representações, enquanto que os objetos tidos como femininos são limitados a uma exterioridade dos seus relacionamentos com a família, os amigos e os lugares reconhecidos socialmente como a casa. 
Será que essa avaliação resume e comporta o protagonismo das mulheres riograndenses? Há um encobrimento delas nos gestos de coleta museal que leva a sociedade a reconhecer, na materialidade dos acervos, naturalizações de representações de gênero?

Examinar o lugar das histórias das mulheres rio-grandenses e brasileiras na perspectiva dos objetos que foram musealizados no MJC é perceber como circulam as questões de gênero nas memórias sociais construídas no Museu que trabalha com a história do Rio Grande do Sul. É, também, compreender o trabalho das mulheres que foram responsáveis pela construção de discursos e narrativas em suas ordenações a respeito do próprio gênero.

No tocante ao tema gênero e mulheres nos museus, é ainda escassa a literatura referencial. Maiormente as investigações produzidas manifestam interesse em explorar as exposições museológicas, em que posso destacar os trabalhos das autoras Aída Rechena (2011a, 2011b), Vânia Carvalho (2008), Irene Vaquinhas (2014) e Joana Angélica Silva (2016). Há também algumas discussões com perfil mais biográfico das histórias das mulheres. Em todos os casos, acabam contribuindo para ampliação de reflexões, diálogos e produção de conhecimentos que reforcem a importância das investigações científicas dos processos e procedimentos dos museus e neles. Na produção de história, memória e identidades femininas de um museu, há gravidade na elaboração dos produtos da curadoria institucional.

Convém lembrar que a instituição museal compartilha, entre outras experiências, informações e conhecimentos produzidos, e, no caso do MJC, o principal interesse da instituição foi, e ainda é, didatizar os objetos para a aprendizagem de escolares. Todavia, as seleções de memórias para os estudantes precisam ser problematizadas no ambiente museal, visto que ocasionam tensões entre as reflexões produzidas e o aprendizado do pensar historicamente.

A relação escola e museu é inerente às interfaces educativas museais do MJC. Estas não se resumem à complementaridade de conteúdo, mas abrangem a interação e, sobretudo, a reflexão dada pelo estranhamento, bem como por estética, sensibilidades, sociabilidades, visível e invisível.

A seleção, inclusão e exclusão dos conteúdos abrangidos pelos objetos, pelos textos, pelas imagens e por outros recursos de aprendizagem para didatização histórica estão impregnados de diferenças e de multiplicidades culturais, apresentadas em método próprio do Museu. A intitulação foi decorrência dos direcionamentos de programas e projetos para essa função, mas também se deu pelo expressivo quantitativo de público, formado por escolares, 
provavelmente, resultado da identificação do Museu como figurativo da história regional musealizada.

A parte de visitação de escolas ao MJC é uma possibilidade interessante e necessária a se avaliar, caso para outro artigo. Mas o que cabe para este, é apresentar que a conveniência dessa relação se deu por meio da didatização adequada pelo Museu aos conteúdos escolares que tratam da história do Rio Grande do Sul. Isto feito pela manutenção das salas expositivas e dos objetos temáticos na abordagem cronológica do modelo de escrita da história e da narrativa oficial, iniciada com a luta pela ocupação do território, sobrevindo o período escravista, o império e a república brasileira e rio-grandense.

Vale afirmar que, além de conferir identidade, essa maneira de historiar do MJC esteve encarregada de "inventar tradições". Sobre a formação histórica, o respaldo teórico se dá no diálogo com Jörn Rüsen (2014). Para o autor, a formação histórica passa pela consciência histórica adquirida no aprendizado histórico, prometendo experiência prática de interpretar o mundo. É uma competência adquirida pelo saber, pela subjetividade e pela prática, possibilitadas por contextos abrangentes, como o espaço museológico. O Museu, ao olhar os objetos no perfil de gênero, é ambiente de experiências do presente, que dá possibilidades para perspectivas futuras de igualdade, equidade e empatia de gênero.

$\mathrm{Na}$ classificação dos objetos, o Museu estabeleceu 29 coleções, característica do alto dos seus 116 anos: armas, arreamentos, artes náuticas, bandeiras, bibliografias, condecorações, documentos, escravista, etnologia, heráldica, iconografia, indumentárias, instrumentos musicais, instrumentos de uso pessoal, máquinas, medalhas, numismática, objetos de uso pessoal, objetos decorativos, tesserologia, utensílios domésticos, trabalhos, e viaturas, entre outras. Tais catalogações indicam no presente, o passado e o futuro das representações que o Museu adotou em sua historicidade.

Elas podem ser questionadas, visto que atendem a noção colecionista dos primeiros museus, transformada no século XIX pela assimilação científica do mundo (SUANO, 1986). Com a função social voltada para a educação civilizadora e massificadora, no século XX, tais categorias classificatórias se explicam como método pedagogizado, disciplinar e didático para entendimento da história (RÜSEN, 2007). Ressalta-se que o MJC foi criado num contexto positivista, enciclopédico e evolucionista peculiar dessas instituições do final do século XIX e início do XX, que lhes são pares nacionais e internacionais.

Suas coleções foram formadas aos moldes dessa compreensão institucional, funcional e histórica. Segundo Ana Celina Silva (2018), nos seus primeiros 50 anos, os objetos eram 
voltados para conciliar as funções educativa e científica, o que nesta investigação aponta para uma permanência no tempo presente.

Especificamente a respeito das doações e dos doadores no período de 1995-1998, o MJC incorporou 143 peças. Foram objetos classificados nas coleções de armas, bandeiras, documentos, iconografias, utensílios domésticos, indumentárias, instrumentos de trabalho, máquinas, medalhas, mobiliário, numismática, objetos decorativos, utensílios domésticos, uso pessoal, medalhas e tesserologia.

$\mathrm{Na}$ análise do teor das coleções, é possível reconhecer que os intelectuais mediadores, internos ao museu (funcionários) e externos (doadores), têm consciência do aperfeiçoamento da transformação do processo de musealização para um contexto de seleção mais utilitário dos objetos, para exibição e formação histórica (RÜSEN, 2007). Provavelmente, o processo de musealização, sua problematização das informações e pesquisas, é que estivesse necessitado de uma análise crítica do método, com percepção dos erros e das mudanças cabíveis.

Desse quantitativo dos 143 artefatos, 53\% deles foram doados por mulheres. Não satisfeitas, muitas doadoras retornavam invariavelmente com mais transferências. $\mathrm{O}$ caráter dessas doações era impessoal e incondicional. As doadoras não se interessavam em deixar registradas suas marcas pessoais, em visibilizar suas vivências no Museu, de sair de seus papéis tradicionais da vida cotidiana. Muitas dessas doações, inclusive, não têm assinaturas nas fichas de entrada da documentação museal, como define a regra. A preocupação não era fazer história, mas legitimar posições tradicionais de esposas, filhas, noras, parentes e amigas nas escolhas políticas, econômicas, sociais, culturais dos homens a quem atribuíam objetos.

No universo das doações, destacam-se as coleções de documentos (29\%), composta de peças de regulamentos, títulos de eleitor, passaportes, diplomas, nomeações; iconografia (14\%), com fotografias e estatuárias; e um empate técnico para os objetos classificados pela composição da documentação museológica no sistema Donato, como utensílios domésticos (bengalas, óculos, frascos, missais) e instrumentos de trabalho (13\%).

O que levou as mulheres ao ato de doação pode ser explicado conforme já expôs Regina Abreu (1996) como "fabricação do imortal", intento de imortalizar maridos, parentes ou elementos das memórias pessoais e coletivas artificialmente, ou produzir memória e história, reafirmando o papel legítimo da classe e do grupo a quem pertenciam. Ao escolherem fazer as doações, constituíram lembranças e definiram esquecimentos na dialética da memória social, oportunizando buscar no Museu, sempre que desejosas, as lembranças (RICOUER, 2007). 
Peças que caracterizassem as suas histórias e memórias não tiveram procedência de aquisição, o que facilita interpretar que as abordagens de diferenciação de gênero no Museu se dão no âmbito das relações sociais e de poder internalizadas na sociedade. A instituição museal reafirma essas identificações nas representações provenientes da própria sociedade. Mesmo na singularidade das doações por mulheres, o objeto mantém sua significância definida como símbolos de distinção e na dicotomia público-privado sobre as histórias femininas. Elas também configuram práticas e constituem discursos de estereótipos e insignificância sobre a posição privilegiada dos homens na musealização da memória. Tal efeito mostra que, no final, as doações e seleções que o Museu faz na incorporação de seus objetos são a construção de uma história inacabada e pronta para as revisões.

\section{Considerações finais}

$\mathrm{O}$ artigo procurou mostrar aspectos de ausência e de presença das histórias das mulheres nas representações dos acervos incorporados no MJC, num período específico de 1995-1998. Evidenciou que esta construção passa pela interpretação e significação de intelectuais mediadores, cujas relações de poder estão incutidas em seus saberes e fazeres, de modo que ressonam em suas práticas.

Verifiquei ainda que as mulheres, como agentes da musealização nas operações discursivas e narrativas das histórias do seu próprio gênero, não são interativas. Elas se mantêm fora das esferas de representatividade e de contribuição, em favor dos padrões hierárquicos e do posicionamento masculino presente na história rio-grandense.

Nem as funcionárias, nem as doadoras se colocam na história contada pelos homens através dos objetos do Museu. Seguem mostrando que suas experiências são pouco ou talvez nada conciliatórias com trabalho, vida social, e história, conforme aponta o conceito das coleções do Museu. Suas próprias falas definidas nos atos de seleção e de doação não revelam, pela cultura material preservada e difundida no MJC, suas opressões, lutas e dificuldades. Suas próprias existências como sujeitos e agentes históricos são postas em invisibilidade e distinção, segundo os acervos do MJC.

A impressão apontada pelo texto é de que os objetos museológicos do MJC, como fonte de conhecimento, informam, mas não formam conhecimentos aptos e desafiadores a reformular diferenças historicamente construídas. Isso em decorrência da estreiteza no processo de musealização, que contribui para uma comunicação de ações educativas e 
culturais desestimulantes para as reflexões das mudanças e das permanências do passado no presente, nas questões das histórias das mulheres no MJC. Nessa perspectiva, elas seguem condicionadas a uma memória do grupo que mantém os poderes na política patriarcal e discriminatória. a instituição persevera como "recolhedor passivo" (BITTENCOURT, 2005).

\section{Notas}

${ }^{1}$ O MJC não possui plano museológico e de gestão do acervo. O documento é fundamental para estabelecer estratégias e os rumos institucionais. Previsto na Lei n. 11.904/2009, o instrumento de gestão prevê todos os programas e projetos, configurando direcionamento das ações e atividades museológicas.

${ }^{2}$ Evento embrionário na organização do Grupo de Trabalho de História Cultural da ANPUH, coordenado por Sandra Jatay Pesavento e Francisco Marshall, em 3 de outubro de 1997, cuja palestra foi ministrada por François Hartog. (MJC, 1998, p. 21)

\section{Referências Bibliográficas}

ABREU, Regina. A fabricação do imortal: memória, história e estratégia de consagração no Brasil. Rio de Janeiro: Rocco, 1996.

BAUDRILLARD, Jean. O sistema dos objetos. São Paulo: Perspectiva, 1968.

BENJAMIN, Walter. Sobre o conceito de História. In: Obras escolhidas: magia e técnica, arte e política: ensaios sobre literatura e história da cultura. São Paulo: Brasiliense, 1987. v. 1.

BITTENCOURT, José N. Receita para a refeição cotidiana dos museus. Revista do Patrimônio Histórico e Artístico Nacional, n. 31, p. 149-163, Brasília, DF: MINC/IPHAN, 2005.

CARVALHO, Vânia Carneiro de. Gênero e artefato. São Paulo EDUSP, 2008.

CHARTIER, Roger. A beira da falésia: a história entre incertezas e inquietude. Porto Alegre: Editora da Universidade, 2002.

GONÇALVES, Andréa Lisly. História \& gênero. Belo Horizonte: Autêntica, 2006.

GOMES, Ângela de Castro; HANSEN, Patrícia Santos. Intelectuais mediadores: práticas culturais e ação política. Rio de Janeiro: Civilização Brasileira, 2016.

HARTOG, François. Regimes de historicidade: presentismo e experiências do tempo. Belo Horizonte: Autêntica, 2015.

MUSEU JULIO DE CASTILHOS (MJC). Relatório de gestão 1995-1998. 1998. 
NASCIMENTO, Rosana A. D. O objeto museal, sua historicidade e implicações na ação documental e na dimensão pedagógica do Museu. Lisboa: Centro de Estudos de Sociomuseologia, 2002. v. 11.

POSSAMAI, Zita R. As artimanhas do percurso museal: narrativas sobre os objetos e peças de museu. Mouseion (Revista do Museu e Arquivo Histórico La Salle), v. 4, p. 64-72, jan./jun. 2010.

RAMOS, Francisco Régis Lopes. A danação do objeto: o museu no ensino de História. Chapecó: Argos, 2004.

RAMOS, Francisco Régis Lopes. As Tramas do Objeto no Ensino de História. Anais do Museu Histórico Nacional, v. 39, p. 285-306, 2007.

RECHENA, Aída. Museologia social e gênero. Cadernos do CEOM, v. 27, n. 41. p. 153 174, 2011a.

RECHENA, Aída. Sociomuseologia e género: imagens da mulher em exposições de museus portugueses. Tese (Doutorado em Museologia) - Universidade Lusófona de Humanidades e Tecnologias, Lisboa, 2011b. Disponível em: http://www.museologiaportugal.net/files/upload/doutoramentos/aida_rechena.pdf. Acesso em: 2016.

REDE, Marcelo. História e cultura material. In: VAINFAS, Ronaldo; CARDOSO, Ciro F. (org.). Novos domínios da história. Rio de Janeiro: Elsevier Brasil, 2011.

REDE, Marcelo. A História a partir das coisas: tendências recentes nos estudos de cultura material. Anais do Museu Paulista: História e Cultura Material, São Paulo, v. 4, n. 1, p. 265-282, 1996.

REIS, José Carlos. O desafio historiográfico. Rio de Janeiro: Ed. FGV, 2010.

RICOUER, Paul. A memória, a história, o esquecimento. Campinas, SP; UNICAMP, 2007.

RICOUER, Paul. Tempo e narrativa: a intriga e a narrativa histórica. São Paulo: WMF;

Martins Fontes, 2010. v. 1.

ROCHE, Daniel. História das coisas banais. Lisboa: Teorema, 1998.

RÜSEN, Jörn. Aprendizagem histórica: fundamentos e paradigmas. Curitiba: WA Editores, 2012. p. 151-166.

RÜSEN, Jörn. Cultura faz sentido: orientações entre o ontem e o amanhã. Petrópolis, R:

Vozes, 2014.

RÜSEN, Jörn. História viva: teoria da história: formas e funções do conhecimento histórico. Brasília: Ed. Universidade de Brasília, 2007. 
SILVA, Ana Celina F. da. Investigações e evocações do passado: o Departamento de História Nacional do Museu Julio de Castilhos (Porto Alegre, RS, 1925-1939). 2018. Tese (Doutorado em História) - Universidade Federal do Rio Grande do Sul, Porto Alegre, 2018.

SILVA, Joana Angélica. A representação das mulheres negras nos museus da cidade de Salvador, Bahia. In: TEIXEIRA, Sidélia (org.) Patrimônio e museus na contemporaneidade. Salvador: EDUFBA, 2016.

SILVEIRA, Andréa R. da. O Museu Julio de Castilhos no período 1960-1980: acervos, discursos, representações e práticas através de uma exposição museológica. 2011. 172 f. Dissertação (Mestrado) - Curso de Patrimônio Cultural, Universidade Federal de Santa Maria, Santa Maria, 2011.

STRANSKY, Zbynek Z. Introduction à l'étude de la muséologie. Destinée aux étudiants de l'École Internationale d'Été de Muséologie - EIEM. Brno: Université Masaryk, 1995.

SUANO, Marlene. O que é museu. São Paulo: Brasiliense, 1986.

VAQUINHAS, Irene M. Museus do feminino, museologia de género e o contributo da história. Midas - Museus e estudos interdisciplinares, n. 3, 2014. 